\title{
Ertapenem-Induced Reduction in Valproate Levels: Case Report and Review of the Literature
}

\author{
Duane Bates, Michael Parkins, and Keltie Duggan
}

\section{INTRODUCTION}

$T^{\mathrm{b}}$ The concomitant use of carbapenems and valproate is not recommended because carbapenems may decrease serum concentrations of valproate. ${ }^{1,2}$ Increasing the dose of valproate may not compensate for the reduction, which puts the patient at risk for recurrent seizures. Therefore, close monitoring of valproate levels is necessary when initiating a carbapenem antibiotic in patients whose condition has been stabilized with valproate therapy.

Several case reports of significant reductions in serum valproate concentrations following initiation of carbapenem antibiotics have been published. To the authors' knowledge, however, there has been no published systematic review of the carbapenem-valproate interaction. We report a case of ertapenem-induced reduction in valproate concentration and describe the extent, clinical relevance, potential mechanisms, and therapeutic options for management of the carbapenemvalproate interaction.

\section{CASE REPORT}

A 58-year-old woman was admitted to hospital with a 7-day history of malaise, low-back pain, and confusion.* Pertinent aspects of the medical history included multiple sclerosis, seizure disorder, and recurrent urinary tract infections. Medications before admission included calcium carbonate $500 \mathrm{mg}$ twice daily, vitamin D 1000 IU daily, alendronate $70 \mathrm{mg}$ weekly, amitriptyline $10 \mathrm{mg}$ at bedtime, baclofen $10 \mathrm{mg}$ twice daily, furosemide $20 \mathrm{mg}$ daily, potassium chloride $40 \mathrm{mmol}$ twice daily, lansoprazole $15 \mathrm{mg}$ daily, brimonidine $0.2 \%$ one drop into each eye twice daily, timolol $0.5 \%$ one drop into each eye twice daily, and latanoprost $50 \mu \mathrm{g} / \mathrm{mL}$ one drop into each eye daily at bedtime. The patient was also taking valproate $250 \mathrm{mg}$ 3 times daily.

\footnotetext{
*The patient gave verbal consent for publication of this case report.
}

The patient's seizure condition had been stabilized by the valproate therapy, and there had been no change in the dose over the previous 3 years. The patient's most recent seizure had occurred 7 months before the admission. Seven weeks before admission, a valproate trough of $556 \mu \mathrm{mol} / \mathrm{L}$ (normal range 350-700 $\mu \mathrm{mol} / \mathrm{L}$ ) was measured in a blood sample drawn before the morning dose. A urine sample obtained for culture 10 days before admission grew a multidrug-resistant strain of Escherichia coli (more than $1 \times 10^{8}$ colony-forming units per litre), and a 14-day course of nitrofurantoin $50 \mathrm{mg} 4$ times daily was initiated. The patient had reported allergies (in the form of a rash) to cephalosporins and phenytoin.

The patient was bedridden and had a permanent indwelling Foley catheter. She was alert and oriented. A neurological examination showed diffuse generalized weakness and delayed speech. An abdominal examination revealed mild tenderness on palpation. The results of head and neck, cardiovascular, respiratory, and musculoskeletal examinations were unremarkable. The patient was hemodynamically stable and afebrile. The white blood cell and neutrophil counts were normal at the time of admission. Serum creatinine was $55 \mu \mathrm{mol} / \mathrm{L}$ (normal range $35-100 \mu \mathrm{mol} / \mathrm{L}$ ), with an estimated creatinine clearance of $82 \mathrm{~mL} / \mathrm{min}$. A sample for determination of valproate level was not drawn at the time of admission. Urinalysis showed that the urine was cloudy, with a $\mathrm{pH}$ of 6 (normal range 5-8.5), was negative for nitrites, and had a white blood cell count above 30 per high-power field (normal range 0-5 per high-power field). The results of urine culture were positive for Candida albicans, with a colony count of $1 \times 10^{7}$ to $1 \times 10^{8}$ colony-forming units per litre. The results of blood culture were negative.

Acute pyelonephritis was diagnosed. The nitrofurantoin was discontinued, and all other preadmission medications were continued. The patient was given a single dose of ceftriaxone $1 \mathrm{~g}$ in the emergency department with no adverse reaction. On day 2 of the admission, after review of the results of earlier urine 
cultures, the patient was switched to amikacin $320 \mathrm{mg}$ (4.3 $\mathrm{mg} / \mathrm{kg}$ ) IV every $8 \mathrm{~h}$. On day 3, the infectious diseases service was consulted. At that point, the amikacin was discontinued because of the potential risk of ototoxicity. The patient had received a 10-day course of gentamicin 4 weeks before admission for Providencia stuartii infection of the urinary tract. Ertapenem 1 g IV daily was initiated, but no therapy was recommended for the Candida albicans infection, as this infection was thought to be due to colonization. The Foley catheter was removed, and intermittent catheterization (every 8 h) was initiated.

On day 5 of the admission, the clinical pharmacist suggested that the trough valproate level be measured before the morning dose, because of the potential for an interaction between ertapenem and valproate. The trough level was $48 \mu \mathrm{mol} / \mathrm{L}$ (Figure 1). The valproate dose was doubled, to 500 mg 3 times daily. On day 11, the serum valproate level before the morning dose was $88 \mu \mathrm{mol} / \mathrm{L}$, and the patient was discharged back to the long-term care facility, where she received parenteral antibiotic therapy with ertapenem for an additional 7 days. Instructions were given to decrease the dose of valproate to $250 \mathrm{mg} 3$ times daily after completion of antibiotic therapy. However, this decrease was mistakenly implemented early, on day 16 after the admission (i.e., 5 days after discharge). On day 18 after the admission (i.e., 7 days after discharge), the ertapenem was discontinued; at that time, repeat testing revealed that the valproate level was $60 \mu \mathrm{mol} / \mathrm{L}$.
The dose was again increased to $500 \mathrm{mg} 3$ times daily. Despite prolonged subtherapeutic valproate, no seizure activity was observed. On day 34 after the admission, the valproate level was $692 \mu \mathrm{mol} / \mathrm{L}$. On day 47, the dose of the drug was decreased to $250 \mathrm{mg} 3$ times daily, and at follow-up on day 60 , the level was $392 \mu \mathrm{mol} / \mathrm{L}$.

\section{DISCUSSION}

A systematic review of the literature was conducted to identify publications describing the interaction between carbapenems and valproate. The search terms "meropenem", "imipenem", "ertapenem", "doripenem", "valproic acid”, and "valproate" were used to search PubMed, Ovid, EMBASE, International Pharmaceutical Abstracts, and Reactions Weekly (for January 1950 to September 2009). A total of 23 individual case reports and 3 case series (with a total of 147 patients) were identified. Two case reports were excluded from the analysis, one because valproic acid levels were not reported $^{3}$ and the other because the report was in Korean and translation was not possible. $^{4}$

\section{Case Reports}

Twenty-one cases of an interaction between a carbapenem and valproate were reviewed. Valproate was used for seizure prophylaxis ( 4 cases), ${ }^{5,6}$ acute symptomatic seizures (5 cases),,$^{7-10}$ and treatment of epilepsy $(12 \text { cases })^{11-19}$ (Table 1$)$. An average of

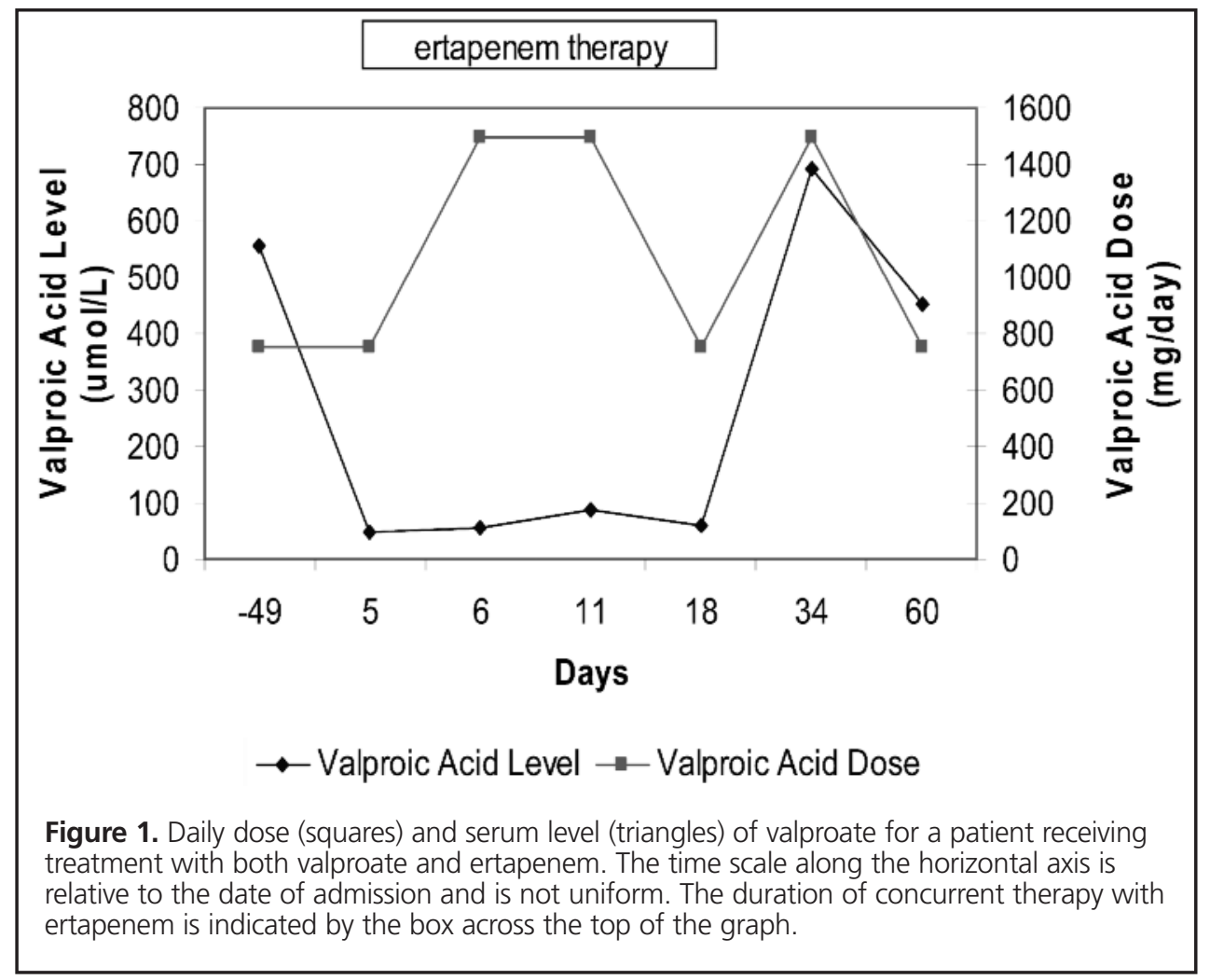


3.2 days of concurrent therapy resulted in reduction of valproate levels by an average of $73 \%$ (range $41 \%-100 \%$ ). A median increase in the valproate dose of $850 \mathrm{mg} /$ day (interquartile range [IQR] 728-1238 mg/day) did not result in achievement of therapeutic serum concentration of valproate for any patient (median valproate level $104 \mu \mathrm{mol} / \mathrm{L}$ [IQR 68-132 $\mu \mathrm{mol} / \mathrm{L}])$. In 7 patients the carbapenem was changed to an alternative antibiotic, and a period of 1 to 20 days was required for serum valproate levels to return to the therapeutic range. ${ }^{6-8,10-14,18}$ In 4 patients the valproate was discontinued, and an alternative antiseizure medication was prescribed. ${ }^{5,9,17,18}$ Two patients required adjunctive seizure therapy. ${ }^{8}$ Two patients were rechallenged with meropenem, and experienced recurrent drops in valproate levels, which resulted in seizures. ${ }^{13,16}$ The limitations of these case reports included a lack of information about the patient's medical history, concomitant drug therapy, laboratory data (specifically creatinine clearance), and time at which samples were drawn for determining valproate levels.

Another report described a 10-year-old girl who was being treated for seizures with valproate $5 \mathrm{mg} / \mathrm{kg}$ every $12 \mathrm{~h}$ (usual maintenance dose 30-60 mg/kg per day) and carbamazepine. ${ }^{20}$ The dose of carbamazepine and the baseline valproate level were not reported. After 2 days of treatment with panipenembetamipron, the frequency of seizures increased (serum concentration of valproate $184 \mu \mathrm{mol} / \mathrm{L}$ ). The carbamazepine level was $38 \mu \mathrm{mol} / \mathrm{L}$ before and $39 \mu \mathrm{mol} / \mathrm{L}$ during the panipenembetamipron therapy (normal range $20-50 \mu \mathrm{mol} / \mathrm{L}$ ). Phenobarbital was substituted for the valproate, which led to control of the seizures. The panipenem-betamipron was continued for 53 days for treatment of pleural empyema.

\section{Case Series}

Spriet and others ${ }^{21}$ conducted the most comprehensive review of the meropenem-valproate interaction published to date. They reviewed 39 patient charts. Valproate was used for treatment of acute seizures $(n=24)$, treatment of epilepsy $(n=12)$, prophylaxis of seizure $(n=2)$, and treatment of mood disorder $(n=1)$. The mean daily valproate dose $( \pm$ standard deviation) was $1.6 \pm 0.68 \mathrm{~g}$ (range $0.4-4 \mathrm{~g}$ ). The mean daily meropenem dose was $2.67 \pm 1.4 \mathrm{~g}$ (range $0.5-6 \mathrm{~g}$ ). The mean creatinine clearance was $65.73 \pm 32 \mathrm{~mL} / \mathrm{min}$ (range 12.3$112 \mathrm{~mL} / \mathrm{min})$.

Twenty-nine of the 39 patients received meropenem after initiation of valproate. The mean baseline valproate level was $446 \pm 146 \mu \mathrm{mol} / \mathrm{L}$ (range 277-770 $\mu \mathrm{mol} / \mathrm{L}$ ). During concomitant meropenem therapy, the mean valproate level fell to $156 \pm 83 \mu \mathrm{mol} / \mathrm{L}$ (range < 21 to $298 \mu \mathrm{mol} / \mathrm{L}$ ), which represents an average drop of $66 \% \pm 17 \%$ (range 34\%-92\%). Nineteen patients experienced a reduction in valproate level within $24 \mathrm{~h}$. No known proconvulsive drugs had been added to the patients' regimens.

The other 10 patients received valproate after initiation of meropenem. Plasma valproate concentrations remained subtherapeutic, despite IV administration of an adequate loading dose (mean $21 \mathrm{mg} / \mathrm{kg}$ ) and maintenance dose (mean $31.5 \mathrm{mg} / \mathrm{kg}$ daily). The mean plasma concentration of valproate during concomitant use of valproate and meropenem was $82 \pm 69 \mu \mathrm{mol} / \mathrm{L}$ (range $<21$ to $257 \mu \mathrm{mol} / \mathrm{L}$ ).

Nine of the 39 patients had an extra valproate loading dose (mean $944 \mathrm{mg}$ ). For 19 patients, the maintenance dose of valproate was increased while they were receiving the combination of meropenem and valproate (mean increase 146\%). For 8 patients, increasing the valproate dose did not result in elevation of plasma concentrations of the drug. In one patient, the maintenance dose of valproate was increased to $12 \mathrm{~g} /$ day (usual maintenance dose $10-60 \mathrm{mg} / \mathrm{kg}$ daily). This was the only patient for whom plasma concentrations of valproate reached therapeutic levels during the course of concomitant therapy (361 $\mathrm{mol} / \mathrm{L})$. After discontinuation of the meropenem, it took an average of 8 days for valproate levels to return to the therapeutic range. Mean plasma concentration of valproate after the combination therapy was $385 \mu \mathrm{mol} / \mathrm{L}$.

Spriet and others ${ }^{21}$ reported that lack of documentation in 19 cases prevented determination of the clinical impact of the drug interaction. Twenty-five of the 39 patients died during the hospital stay. The interaction might have contributed to an increase in seizure activity $(n=3)$, a change in electroencephalography recordings $(n=2)$, or both $(n=5)$. For 5 patients, the valproate was discontinued and replaced with alternative antiepileptic drug therapy; 2 patients required adjunctive antiepileptic medications.

Haroutiunian and others ${ }^{22}$ conducted a chart review of 36 adult patients ( 29 men, 7 women; mean age 59 years) who had received concomitant therapy with valproate and meropenem. The mean daily doses were valproate $2.04 \pm 0.07 \mathrm{~g}$ and meropenem $4.88 \pm 0.25 \mathrm{~g}$. The mean plasma concentration of valproate deceased from $352 \pm 31 \mu \mathrm{mol} / \mathrm{L}$ to $68.6 \pm 15 \mu \mathrm{mol} / \mathrm{L}$ during concomitant therapy. Five patients had samples drawn for valproate measurement within $24 \mathrm{~h}$ after initiation of meropenem, and the mean plasma valproate concentration for these patients was $68.6 \pm 22.2 \mu \mathrm{mol} / \mathrm{L}$. Haroutiunian and others $^{22}$ also reported the reduction in valproate concentration in relation to the dose of meropenem. The mean decrease in valproate concentration was $83.4 \%$ for patients receiving highdose meropenem ( $6 \mathrm{~g} /$ day $)$ and $81.0 \%$ for patients receiving standard-dose meropenem (<3 g/day). Different daily doses of valproate were associated with a similar reduction in concentration of valproic acid. Valproate levels remained low for 7 days after discontinuation of meropenem and gradually increased from 8 to 14 days to levels comparable to those before initiation of meropenem. 


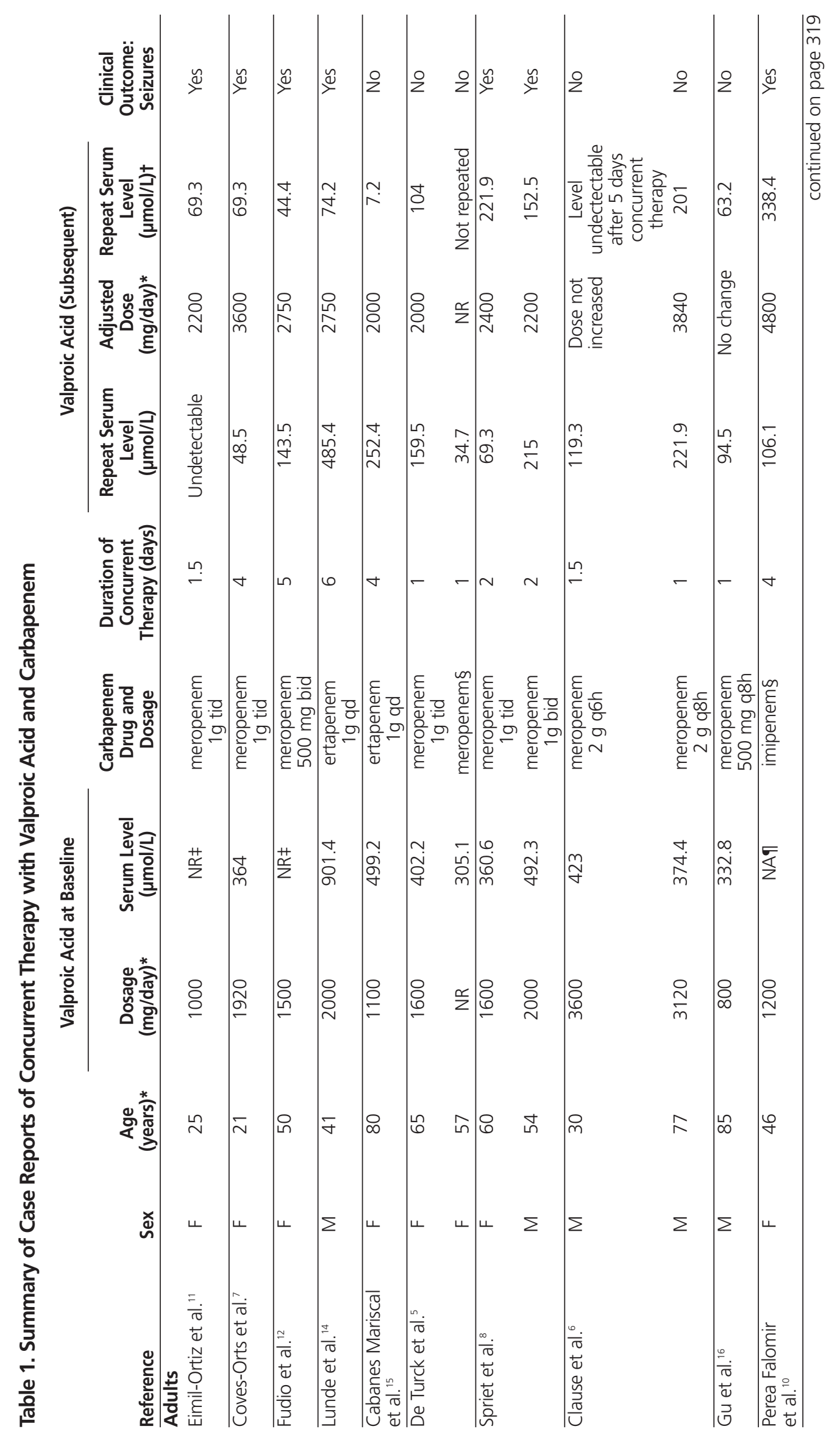




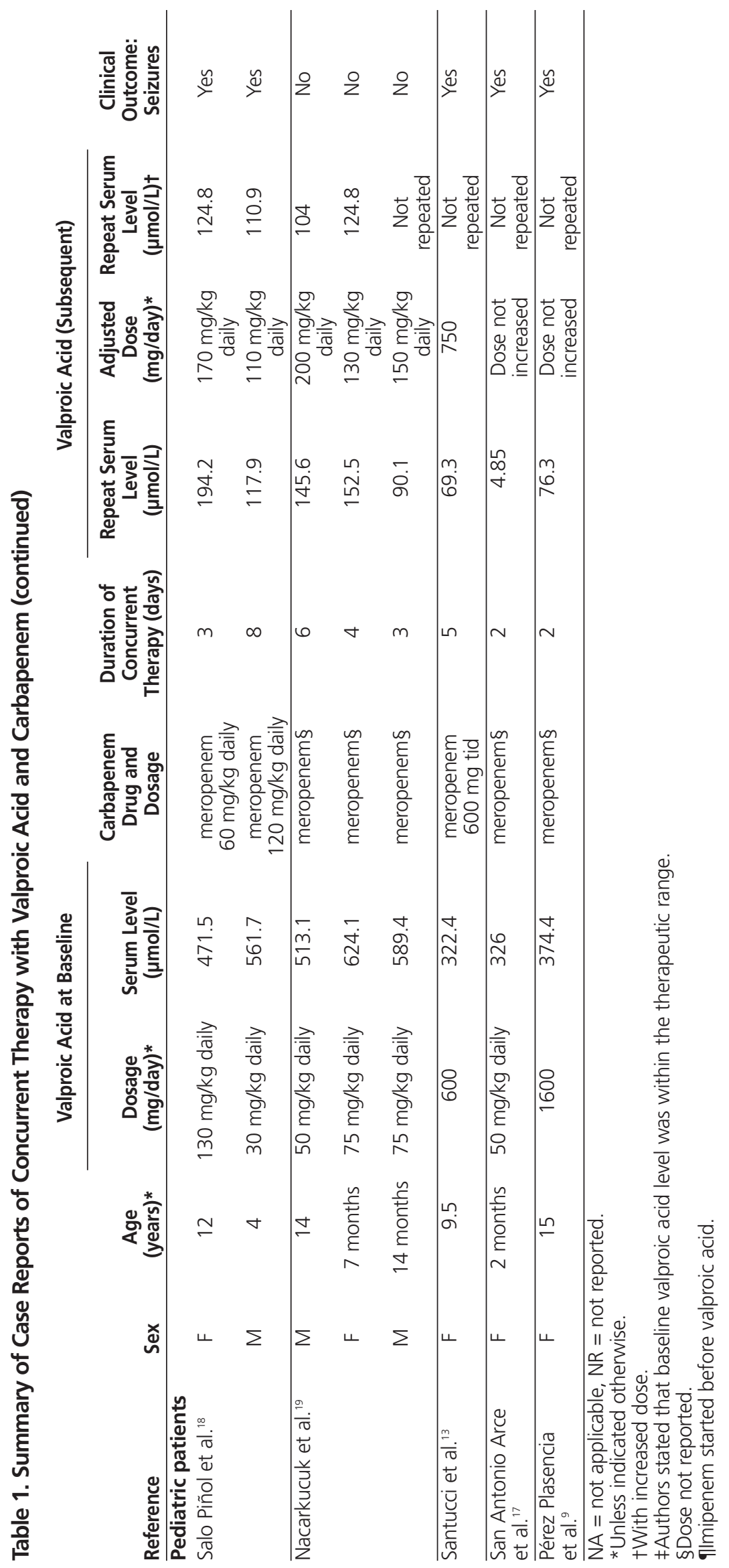


Borobia and others ${ }^{23}$ reviewed the concomitant use of meropenem and valproate for patients seen over a 5-year period. A total of 72 patients (63 adults and 9 children; 40 males and 32 females) received both drugs simultaneously. The median age was 47.5 years (range 9 months to 86 years). Samples for determination of valproate levels were drawn for 19 patients. The average reduction in valproate level was $74 \%$ (range 34\%-98\%). Four of the patients had seizures, but no further information about these patients was provided.

Doripenem is the newest carbapenem to be released in Canada. The literature search revealed no human cases of interaction between doripenem and valproate. The product monograph $^{24}$ states that the administration of 4 doses of doripenem ( $500 \mathrm{mg}$ every $8 \mathrm{~h}$ ) to 23 healthy male subjects who had been receiving valproate $500 \mathrm{mg}$ every $12 \mathrm{~h}$ for 7 days resulted in a decrease in the mean minimum concentration (by $78 \%$ ), maximum concentration (by $45 \%$ ), and the area under the concentration-time curve ( 0 to $\tau$, where $\tau$ is the dosing interval; by $63 \%$ ) relative to valproic acid alone. A reduction in serum concentration of valproic acid was observed within $12 \mathrm{~h}$ after initiation of doripenem.

\section{Pharmacokinetics of Valproate}

A brief overview of the pharmacokinetics of valproic acid is necessary to identify the possible mechanisms of the valproate-carbapenem interaction. ${ }^{25-27}$ The bioavailability of valproate is $90 \%-100 \%$, and the drug has a volume of distribution of $0.2 \mathrm{~L} / \mathrm{kg}$. Protein binding is substantial, with $90 \%-95 \%$ of administered valproate being bound to albumin, which is saturable. Valproate is eliminated by first-order kinetics and reportedly has an elimination half-life of 5-20 h (mean 10.6 h).

The hepatic metabolism of drugs depends on the flow of blood to the liver, the extent of protein binding, and the level and activity of drug-metabolizing enzymes. Valproate has a low hepatic extraction, and clearance is therefore independent of blood flow. Metabolism of valproate in the liver is extensive. The 3 main metabolic pathways, in order of importance, are glucuronidation catalyzed by uridinediphospho-glucuronyl transferase (UDPGT) (30\%-60\%), B-oxidation (more than $40 \%$ ), and $\Omega$-oxidation (up to $15 \%-20 \%$ ). ${ }^{25-27} \mathrm{Up}$ to $60 \%$ of the drug is excreted as glucuronide conjugates. The metabolites do not appear to have antiepileptic activity. There is minor cytochrome (CYP) P450 metabolism via the CYP2A6, CYP2C9, CYP2C19, and CYP2B6 isozymes. ${ }^{26}$ Less than 7\% of a dose is excreted unchanged in the urine.

\section{Potential Mechanism of Interaction between Valproate and Carbapenem}

Several animal studies have been carried out in attempts to determine the mechanism of the carbapenem-valproate interaction. Some evidence suggests a decrease in valproate absorption. Carbapenems may inhibit the absorption of valproate at the basolateral membrane of the intestinal epithelial cells. $^{28,29}$ Kojima and others ${ }^{30}$ suggested that carbapenems decrease valproate levels through suppression of the enterohepatic circulation.

Increased uptake of valproate into erythrocytes during therapy with carbapenems has also been suggested. ${ }^{31,32}$ Omoda and others ${ }^{31}$ measured valproate levels in plasma, whole blood, and erythrocytes for 2 patients receiving imipenem $500 \mathrm{mg}$ twice daily for 5 and 7 days. Baseline plasma valproate levels were 318 and $351 \mu \mathrm{mol} / \mathrm{L}$. Treatment with imipenem decreased plasma valproate levels to $57 \%$ and $49 \%$ of the original levels, respectively. The concentration of valproate in erythrocytes was about $69.3 \mu \mathrm{mol} / \mathrm{L}$ during treatment with imipenem and fell to undetectable levels within 13-35 days after discontinuation of the carbapenem.

The liver appears to be the key organ involved in the decrease of serum valproate concentrations during concurrent therapy with a carbapenem. Yamamura and others ${ }^{33}$ studied the effects of valproate given intravenously to rats that had undergone nephrectomy or hepatectomy with and without prior treatment with panipenem. Pretreatment with panipenem enhanced the elimination of valproate in the nephrectomized rats but not the hepatectomized rats. Yamamura and others ${ }^{33}$ concluded that panipenem enhanced the rate of metabolism of valproate to valproic acid glucuronide in the liver. Nakajima and others ${ }^{34}$ studied the effects of panipenem, meropenem, and doripenem on valproate in monkeys and rats. They concluded that carbapenems increased production of valproic acid glucuronide, inhibited hydrolysis of valproic acid glucuronide in the liver, and increased clearance of valproic acid glucuronide by hepatocytes and the kidneys, which thereby decreased valproate levels. An in vitro study of pooled human liver microsomes preincubated with meropenem and biapenem showed a $35 \%$ increase in valproate glucuronidation. ${ }^{32}$ In the case reported by Nagi and others, ${ }^{20}$ the fractional excretion of valproate (urinary valproate $\times$ serum creatinine/serum valproate $\times$ urinary creatinine $\times 100$ ) increased from $0.06 \%$ to $0.21 \%$ after $18 \mathrm{~h}$ of panipenem-betamipron therapy.

\section{Management of Carbapenem-Valproate Interaction}

Clinicians have few antibiotic options for the treatment of infections with multidrug-resistant gram-negative organisms. The carbapenems are considered the drugs of choice for treatment of infection with organisms that produce extendedspectrum B-lactamases (ESBLs), as these drugs are highly resistant to hydrolysis by such organisms and are distributed into the body tissues at high concentrations, and there is no inoculum effect. ${ }^{35-37}$ An alternative antibiotic regimen could be considered in the management of an interaction between carbapenem and valproate. 
Tigecycline is one therapeutic option. ${ }^{38,39}$ Renal excretion is a minor route of elimination for this drug, but there are case reports of tigecycline having been used to treat urinary tract infections. ${ }^{40-46}$ Polymyxins have extensive coverage of gramnegative organisms, but their use has been limited by risks of nephrotoxicity (about 20\% of cases) and neurotoxicity (7\%-10\% of cases) ${ }^{35,38,47}$ Furthermore, there is limited information on their pharmacokinetics, pharmacodynamics, standardization of dosing, and safety. Only colistin sulphomethate sodium is available as an IV formulation in Canada. Colistin has been used to treat urinary tract infections caused by multidrug-resistant organisms. ${ }^{48-50}$ Ertapenem was chosen for the patient described in the current case report because carbapenems are the drug of choice for treatment of infections with ESBL-producing organisms and would allow for oncedaily administration at the patient's long-term care facility. The team did not have any experience with the management of a carbapenem-valproate interaction, and it was decided to follow the valproate levels and adjust the dose as necessary.

For a patient whose condition has been stabilized with an anticonvulsant regimen, the clinician might also consider use of an adjuvant seizure medication while the patient is receiving concurrent carbapenem and valproate therapy. This decision would be influenced by the duration of antibiotic therapy and the frequency of seizures. The choice of anticonvulsant would depend on the seizure type, potential adverse effects, interactions with other medications, and comorbid medical conditions. Previous authors have described the management of carbapenem-valproate interactions by switching the valproate to phenobarbital, phenytoin, or clobazam and oxcarbazine, whereas others have added levetiracetam, topiramate, phenytoin, or phenobarbital to the valproate therapy. ${ }^{5,8,9,17,18}$ Adjuvant therapy may be continued for up to 7 days after the carbapenem is discontinued, as it may take 7 days or more for the serum valproate concentration to return to baseline. The serum valproate level may be measured again 7 days after discontinuation of carbapenem.

For some low-risk patients with seizures (e.g., seizure-free for a number of years or requiring seizure prophylaxis after neurosurgery), it may be sufficient to follow the patient's clinical status and to monitor serum valproate levels. In the case reported here, the team chose not to alter the patient's antiepileptic therapy. This case confirmed previous literature reports that an increase in valproate dose does not compensate for the reduction in serum valproate concentration caused by a carbapenem.

\section{CONCLUSIONS}

The carbapenem-valproate interaction has been well documented among both pediatric and adult patients. The interaction does not appear to be influenced by the total daily dose of either valproate or carbapenem. Concurrent therapy may result in a $60 \%$ to $80 \%$ decrease in serum concentration of valproate within the first few days. As a consequence, approximately $20 \%$ of patients had recurrent seizures. There are 4 options for management of this drug interaction. First, an alternative antibiotic could be used instead of carbapenem. If changing the antibiotic is not feasible, an additional anticonvulsant medication could be added to the patient's regimen or the valproate could be switched to another antiepileptic agent, since increasing the valproate dose does not compensate for the reduction in serum valproate levels caused by the carbapenem. In low-risk patients with seizures who are receiving a short course of carbapenem therapy, monitoring serum valproate concentrations may be adequate.

\section{References}

1. Lexi-Comp Online. Lexi-Interact Online. Hudson (OH): Lexi-Comp, Inc; 2010 [cited 2010 Feb 4]. Available from: http://online.lexi.com (subscription required to access content).

2. Drug interactions. In: Micromedex® 2.0 (Healthcare Series) [electronic version]. Greenwood Village (CO): Thomson Reuters (Healthcare) Inc; [cited 2010 Feb 4]. Available from: www.thomsonhc.com (subscription required to access content).

3. Desai J. Perspectives on interactions between antiepileptic drugs (AEDs) and antimicrobial agents. Epilepsia 2008;49 Suppl 6:47-49.

4. Lee SG, Kim JH, Joo JY, Kwon OH. Seven cases of decreased serum valproic acid concentration during concomitant use of carbapenem antibiotics [in Korean]. Korean J Lab Med 2007;27(5):338-343.

5. De Turck BJG, Diltoer MW, Cornelis PJWW, Maes V, Spapen HDM, Camu F, et al. Lowering of plasma valproic acid concentrations during concomitant therapy with meropenem and amikacin. I Antimicrob Chemother 1998;42(4):563-564.

6. Clause D, Decleire PY, Vanbinst R, Soyer A, Hanston P. Pharmacokinetic interaction between valproic acid and meropenem. Intensive Care Med 2005;31(9):1293-1294.

7. Coves-Orts FJ, Borrás-Blasco J, Navarro-Ruiz A, Murcia-López A, Palacios-Ortega F. Acute seizures due to a probable interaction between valproic acid and meropenem. Ann Pharmacother 2005;39(3):533-537.

8. Spriet I, Meersseman W, De Troy E, Wilmer A, Casteels M, Willems L. Meropenem-valproic acid interaction in patients with cefepime-associated status epilepticus. Am J Health Syst Pharm 2007;64(1):54-58.

9. Pérez Plasencia A, Soy D, Nicolas JM. Pharmacokinetic interaction between valproic acid and meropenem [in Spanish]. Med Clin (Barc) 2004;123(1):38-39.

10. Perea Falomir M, Roura Poch P, Higueruelo Demasón S, García Gil VJ. Pharmacokinetic interaction between valproic acid and imipenem [in Spanish]. Farm Hosp 2006;30(5):316-317.

11. Eimil-Ortiz M, Aguirre-Mollehuanca D, Sierra-Limpo A, Fontán-Tirado C, Villar-Villar E. Meropenem and valproic acid: a dangerous combination [in Spanish]. Rev Neurol 2008;46(2):124-125.

12. Fudio S, Carcas A, Piñana E, Ortega R. Epileptic seizures caused by low valproic acid levels from an interaction with meropenem. J Clin Pharm Ther 2006;31(4):393-396.

13. Santucci M, Parmeggiani A, Riva R. Seizure worsening caused by decreased serum valproate during meropenem therapy. J Child Neurol 2005;20(5):456-457.

14. Lunde JL, Nelson RE, Storandt HF. Acute seizures in a patient receiving divalproex sodium after starting ertapenem therapy. Pharmacotherapy 2007;27(8):1202-1205.

15. Cabanes Mariscal MA, Sánchez López P, Alvarez Herranz P, Chamorro Merino G. Pharmacokinetic interaction between vaproic acid and ertapenem. Farm Hosp 2006;30(5):313-315.

16. Gu J, Huang Y. Effect of concomitant administration of meropenem and valproic acid in an elderly Chinese patient. Am J Geriatr Pharmacother 2009;7(1):26-33.

17. San Antonio Arce V, Joyanes Abancens B. Meropenem and valproic acid. An interaction to remember [in Spanish]. An Pediatr (Barc) 2009;70(2):193-194. 
18. Salo Piñol F, Padullés Zamora N, Hidalgo Albert E, Clemente Bautista S, Cabañas Poy MJ, Oliveras Arenas M, et al. Pharmacokinetic interaction between valproic acid and meropenem [in Spanish]. An Pediatr (Barc) 2006;64(1):93-95.

19. Nacarkucuk E, Saglam H, Okan M. Meropenem decreases serum level of valproic acid. Pediatr Neurol 2004;31(3):232-234.

20. Nagi K, Shimizu T, Togo A, Takeya M, Yokomizo Y, Yasutaka S, et al. Decrease in serum levels of valproic acid during treatment with a new carbapenem, panipenem/betamipron. J Antimicrob Chemother 1997; 39(2):295-296.

21. Spriet I, Goyens J, Meersseman W, Wilmer A, Willems L, Van Paesschen W. Interaction between valproate and meropenem: a retrospective study. Ann Pharmacother 2007;41(7):1130-1136.

22. Haroutiunian S, Ratz Y, Rabinovich B, Adam M, Hoffman A. Valproic acid plasma concentration decreases in a dose-independent manner following administration of meropenem: a retrospective study. $J$ Clin Pharmacol 2009;49(11):1363-1369.

23. Borobia AM, Fudio S, Carcas Sansuán AJ. Valproate-meropenem co-administration, an example of information shortcomings in relevant drug interactions [in Spanish]. Med Clin (Barc) 2009;132(20):803-804.

24. Doribax product monograph. Raritan (NJ): Ortho-McNeil-Janssen Pharmaceuticals, Inc; 2009 May.

25. Gidal BE. Valproic scid. In: Murphy JE, editor. Clinical pharmacokinetics. 4th ed. Bethesda (MD): American Society of Health-System Pharmacists; 2008. p. 315-327.

26. Garnett WR, Anderson GD, Collins RJ. Antiepileptic drugs. In: Burton ME, Shaw LM, Schentag JJ, Evans WE, editors. Applied pharmacokinetics and pharmacodynamics: principles of therapeutic drug monitoring. 4th ed. Baltimore (MD): Lippincott Williams \& Wilkins; 2006. p. 492-511.

27. Valproic acid. In: McEvoy GK, editor. AHFS drug information 2003 [database online]. Bethesda (MD): American Society of Health-System Pharmacists; 2009 [updated 2009 Apr; cited 2009 Aug 25]. Available from: http://online.statref.com (subscription required to access content).

28. Torii M, Takiguchi Y, Saito F, Izumi M, Yokota M. Inhibition by carbapenem antibiotic imipenem of intestinal absorption of valproic acid in rats. J Pharm Pharmacol 2001;53(6):823-829.

29. Torii M, Takiguchi Y, Izumi M, Fukushima T, Yokota M. Carbapenem antibiotics inhibit valproic acid transport in Caco-2 cell monolayers. Int J Pharm 2002;233(1-2):253-256.

30. Kojima S, Nadai M, Kitaichi K, Wang L, Nabeshima T, Hasegawa T. Possible mechanism by which the carbapenem antibiotic panipenem decreases the concentration of valproic acid in plasma in rats. Antimicrob Agents Chemother 1998;42(12):3136-3140.

31. Omoda K, Murakami T, Yumoto R, Nagai J, Maeda Y, Kiribayashi Y, et al. Increased erythrocyte distribution of valproic acid in pharmacokinetic interaction with carbapenem antibiotics in rat and human. J Pharm Sci 2005;94(8):1685-1693.

32. Mori, $\mathrm{H}$, Takahashi K, Mizutani T. Interaction between valproic acid and carbapenem antibiotics. Drug MetSab Rev 2007;39(4):647-657.

33. Yamamura N, Imura K, Naganuma H, Nishimura K. Panipenem, a carbapenem antibiotic, enhances the glucuronidation of intravenously administered valproic acid in rats. Drug Metab Dispos 1999;27(6): 724-730.

34. Nakajima Y, Mizobuchi M, Nakumra M, Takagi H, Inagaki H, Kominami $\mathrm{G}$, et al. Mechanism of the drug interaction between valproic acid and carbapenem antibiotics in monkeys and rats. Drug Metab Dispos 2004;32(12):1383-1391.

35. Nicasio AM, Kuti JL, Nicolau DP. The current state of multidrug-resistant gram-negative bacilli in North America. Insights from the Society of Infectious Disease Pharmacists. Pharmacotherapy 2008;28(2):235-249.

36. Pitout JDD, Laupland KB. Extended spectrum B-lactamase-producing Enterobacteriaceae: an emerging public health concern. Lancet Infect Dis 2008;8(3):159-166.

37. Munoz-Price LS, Jacoby GA, Snydman DR. Extended spectrum betalactamases. In: UpToDate online, version 17.2 [database online]. Waltham (MA): UpToDate Inc; [updated 2008 Sep 2; cited 2009 Sep 24]. Available from www.uptodateonline.com (subscription required to access content).
38. Giamarellou H, Poulakou G. Multidrug-resistant gram-negative infections. What are the treatment options? Drugs 2009;69(14):1879-1901.

39. Kelesidis T, Karageorgopoulos DE, Kelesidis I, Falagas ME. Tigecycline for the treatment of multidrug-resistant Enterobacteriaceae: a systematic review of the evidence from microbiological and clinical studies. J Antimicrob Chemother 2008;62(5):895-904.

40. Barbour A, Schmidt S, Ma B, Schiefelbien L, Rand KH, Burkhardt O, et al. Clinical pharmacokinetics and pharmacodynamics of tigecycline. Clin Pharmacokinet 2009;48(9):575-584.

41. Curcio D. Treatment of recurrent urosepsis with tigecycline: a pharmacological perspective J Clin Microbiol 2008;46(5):1892-1893.

42. Krueger WA, Kempf VAJ, Peiffer M, Nagele U, Unertl KE, Schroeder TH. Treatment with tigecycline of recurrent urosepsis caused by extendedspectrum-ß-lactamase-producing Escherichia coli. J Clin Microbiol 2008;46(2):817-820

43. Gallagher JC, Rouse HM. Tigecycline for the treatment of Acinetobacter infections: a case series. Ann Pharmacother 2008;42(9):1188-1194.

44. Cunha BA. Pharmacokinetic considerations regarding tigecycline for multidrug-resistant (MDR) Klebsiella pneumoniae or MDR Acinetobacter baumannii urosepsis [letter]. J Clin Microbiol 2009;47(5):1613.

45. Cunha BA, McDermott B, Nausheen S. Single daily high dose tigecycline therapy of a multidrug resistant (MDR) Klebsiella pneumoniae and Enterobacter aerogenes nosocomial urinary tract infection. J Chemother 2008;19(5):753-754.

46. Reid GE, Grim SA, Aldeza CA, Janda WM, Clark NM. Rapid development of Acinetobacter baumannii resistance to tigecycline. Pharmacotherapy 2007;27(8):1198-1201.

47. Falagas ME, Kasiakou SK. Colistin: the revival of polymyxins for the management of multidrug-resistant gram-negative bacterial infections. Clin Infect Dis 2005;40(9):1333-1341. Erratum in: Clin Infect Dis 2006;42(12):1819 (dosage error in article text).

48. Pintado V, San Miguel LG, Grill F, Mejía B, Cobo J, Fortún J, et al. Intravenous colistin sulphomethate sodium for therapy of infections due to multidrug-resistant gram-negative bacteria. J Infect 2008;56(3):185-190.

49. Kasiakou SK, Michalopoulos A, Soteriades ES, Samonis G, Sermaides GJ, Falagas ME. Combination therapy with intravenous colistin for management of infections due to multidrug-resistant gram-negative bacteria in patients without cystic fibrosis. Antimicrob Agents Chemother 2005;49(8):3136-3146.

50. Kallel H, Bahloul M, Hergafi L, Akrout M, Ketata W, Chelly H, et al. Colistin as a salvage therapy for nosocomial infections caused by multidrug-resistant bacteria in the ICU. Int J Antimicrob Agents 2006;28(4):366-369.

Duane Bates, BScPharm, ACPR, is a Clinical Practice Leader, Medicine, with the Department of Pharmacy, Peter Lougheed Centre of Alberta Health Services, Calgary, Alberta.

Michael Parkins, MD, MSC, FRCPC, is an Infectious Diseases Physician with the Department of Medicine, Peter Lougheed Centre, Alberta Health Services, Calgary, Alberta.

Keltie Duggan, BA, MD, CCFP, is a Hospitalist Physician with the Department of Family Medicine, Peter Lougheed Centre, Alberta Health Services, Calgary, Alberta.

\section{Address correspondence to:}

Duane Bates

Department of Pharmacy

Peter Lougheed Centre

3500 26th Avenue NE

Calgary AB T1Y 6J4

e-mail: duane.bates@albertahealthservices.ca 